University of Wollongong

Research Online

Faculty of Engineering and Information

Faculty of Engineering and Information

Sciences - Papers: Part A

Sciences

$1-1-2013$

\title{
Estimating the rate of erosion of a silty sand treated with lignosulfonate
}

Buddhima Indraratna

University of Wollongong, indra@uow.edu.au

Rasika Athukorala

University Of Wollongong, rasika@uow.edu.au

Jayan Vinod

University of Wollongong, vinod@uow.edu.au

Follow this and additional works at: https://ro.uow.edu.au/eispapers

Part of the Engineering Commons, and the Science and Technology Studies Commons

Research Online is the open access institutional repository for the University of Wollongong. For further information contact the UOW Library: research-pubs@uow.edu.au 


\title{
Estimating the rate of erosion of a silty sand treated with lignosulfonate
}

\begin{abstract}
This paper describes a theoretical model to capture the rate of erosion of a silty sand based on the principle of conservation of energy. Erosion is considered to begin when the interparticle bonds between grains are broken by hydrodynamic stresses exerted on the soil particles. These detached particles are then suspended and transported by the flow of eroding fluid. It is further assumed that once the particles are fully suspended and have reached the flow velocity, resettlement does not take place. Stabilization of soil particles because of lignosulfonate (LS) treatment is represented by the increased strain energy required to break the interparticle bonds. The equation proposed in this study is based on the shear stress-strain characteristics, mean flow velocity, mean particle diameter, and the packing arrangement of particles. The result of the proposed study is presented in the form of erosion rate versus the hydraulic shear stress. The model is validated with a series of laboratory erosion tests using the Process Simulation Apparatus for Internal Crack Erosion (PSAICE) for different percentages of LS. The model results are in good agreement with the experimental observations. DOI:

10.1061/(ASCE)GT.1943-5606.0000766. (C) 2013 American Society of Civil Engineers.
\end{abstract}

\section{Keywords}

lignosulfonate, erosion, estimating, silty, rate, sand, treated

Disciplines

Engineering | Science and Technology Studies

\section{Publication Details}

Indraratna, B., Athukorala, R. \& Vinod, J. (2013). Estimating the rate of erosion of a silty sand treated with lignosulfonate. Journal of Geotechnical and Geoenvironmental Engineering, 139 (5), 701-714. 


\title{
Estimating the Rate of Erosion of a Silty Sand Treated with Lignosulfonate
}

\author{
Buddhima Indraratna, F.ASCE${ }^{1}$; Rasika Athukorala, S.M.ASCE²; and Jayan Vinod ${ }^{3}$
}

\begin{abstract}
This paper describes a theoretical model to capture the rate of erosion of a silty sand based on the principle of conservation of energy. Erosion is considered to begin when the interparticle bonds between grains are broken by hydrodynamic stresses exerted on the soil particles. These detached particles are then suspended and transported by the flow of eroding fluid. It is further assumed that once the particles are fully suspended and have reached the flow velocity, resettlement does not take place. Stabilization of soil particles because of lignosulfonate (LS) treatment is represented by the increased strain energy required to break the interparticle bonds. The equation proposed in this study is based on the shear stress-strain characteristics, mean flow velocity, mean particle diameter, and the packing arrangement of particles. The result of the proposed study is presented in the form of erosion rate versus the hydraulic shear stress. The model is validated with a series of laboratory erosion tests using the Process Simulation Apparatus for Internal Crack Erosion (PSAICE) for different percentages of LS. The model results are in good agreement with the experimental observations. DOI: 10.1061/(ASCE)GT.1943-5606.0000766. () 2013 American Society of Civil Engineers.
\end{abstract}

CE Database subject headings: Soil erosion; Silts; Sand (soil type); Chemicals.

Author keywords: Erosion rate; Silty sand; Chemical stabilization; Lignosulfonate.

\section{Introduction}

Earth structures such as embankment dams, rail and/or road embankments, canals, and foundations associated with erodible and dispersive soils are in danger of surface and internal erosion (piping). Therefore, it is very important to improve their resistance to erosion in an appropriate and cost-effective manner. Chemical stabilization is an effective technique for controlling erosion. A great deal of research has been carried out on the engineering behavior of stabilized erodible and dispersive soils using traditional admixtures such as lime, cement, gypsum, slag, alum, and fly ash (Perry 1977; Rosewel 1977; Ryker 1977; Machan et al. 1977; Indraratna et al. 2008a,b; Indraratna et al. 2009; Indraratna et al. 1991; Indraratna 1996; Biggs and Mahony 2004). However, traditional chemical stabilizers are not always readily acceptable in Australia because of stringent occupational health and safety issues. They also pose a threat to the environment by changing the soil $\mathrm{pH}$, which often limits the scope of vegetation and also affects the quality of the groundwater. Moreover, traditionally stabilized soil has a pH of 9 (Rollings and Burkes 1999), which often affects the longevity of steel elements in the ground (e.g., fencing) and steel frame structures (Biggs and Mahony 2004; Perry 1977). In addition, other chemical aspects, such as the electrical conductivity

${ }^{1}$ Professor of Civil Engineering and Research Director, Centre for Geomechanics and Railway Engineering, Univ. of Wollongong, Wollongong NSW 2522, Australia (corresponding author). E-mail: indra@uow. edu.au

${ }^{2} \mathrm{Ph} . \mathrm{D}$. Candidate, Centre for Geomechanics and Railway Engineering, Univ. of Wollongong, Wollongong NSW 2522, Australia.

${ }^{3}$ Senior Lecturer, Centre for Geomechanics and Railway Engineering, Univ. of Wollongong, Wollongong NSW 2522, Australia.

Note. This manuscript was submitted on December 14, 2011; approved on July 16, 2012; published online on July 31, 2012. Discussion period open until October 1, 2013; separate discussions must be submitted for individual papers. This paper is part of the Journal of Geotechnical and Geoenvironmental Engineering, Vol. 139, No. 5, May 1, 2013. @ASCE, ISSN 1090-0241/2013/5-701-714/\$25.00. and the cation exchange capacity of the soil, decreases with increasing amounts of admixtures and longer curing times (Chen et al. 2009; Boardman et al. 2001). Moreover, cementitious chemical admixtures reduce the capacity of soil to hold water and carry nutrients, which affects its fertility (Kitchen et al. 1996; Jaynes et al. 1995). Excessive use of traditional admixtures to stabilize soil also affect the yielding capacity of certain soils (Nalbantoglu and Tuncer 2001). In general, chemically treated soil becomes more brittle (Sariosseiri and Muhunthan 2009), which affects the stability of structures, especially during cyclic and impact loading conditions such as those applied to high-speed rail and aircraft runways. To overcome these consequences, an alternative soil stabilizer that improves the soil without harming the environment must be found.

A lignin-based chemical known as lignosulfonate (LS), has shown promise at stabilizing some problematic soils (Puppala and Hanchanloet 1999; Pengelly et al. 1997; Tingle and Santoni 2003; Indraratna et al. 2008a,b; Vinod et al. 2010). Indraratna et al. (2008b) carried out laboratory experiments on dispersive soils treated with LS using the novel Process Simulation Apparatus for Internal Crack Erosion (PSAICE). They concluded that LS improves resistance to erosion, whereas the amount of LS required for silty sand to reach a given increase in erosion resistance is less than that of cement. Therefore, the main focus of this study investigates how well LS can stabilize an erodible soil and develops an analytical model to capture the erosive behavior of this treated soil. The erosion of treated and untreated soils is generally examined in terms of its rate and hydraulic shear stress, to calculate the critical shear stress and coefficient of erosion. The critical shear stress $\tau_{c}$ is defined as the minimum hydraulic shear stress required for erosion to commence (Arulanandan et al. 1975; Sargunan 1976; Shaikh et al. 1988). Fig. 1 shows the variation of the erosion rate with the applied hydraulic shear stress. The critical shear stress was calculated by extrapolating the straight line to the $X$-axis, and the slope of the line represents the coefficient of erosion $(\alpha)$. The difference between the applied hydraulic shear stress and critical shear stress is defined as the excess hydraulic shear stress $\left(\tau_{a}-\tau_{c}\right)$. 
Only a few researchers attempted to correlate the parameters of erosion with the shear or tensile strength of soil (Dunn 1959; Lyle and Smerdon 1965; Kamphuis and Hall 1983; Reddi and Bonala 1997; Hjeldnes and Lavinia 1980). Dunn (1959) used a jet of water to conduct a series of erosion tests on cohesive soils collected from canal beds and found that the critical shear stress varied linearly with the vane shear strength. Kamphuis and Hall (1983) used a flume to conduct a set of erosion experiments on two different soils and concluded that the critical shear stress of over consolidated clayey soils changed linearly with the vane shear strength and unconfined compressive strength. Reddi and Bonala (1997) developed an analytical model for critical shear stress (under seepage erosion) in terms of true cohesion. Indraratna et al. (2009) developed an analytical model to simulate the erosion of soil by capturing its tensile behavior based on the law of conservation of energy. This model captured the erosion of soil by following two steps: (1) the detachment of particles by the eroding fluid, which resulted in a suspended load; and (2) transportation of a suspended load. However, to date, a comprehensive theoretical model that correlates erosive behavior with the most widely used shear strength of chemically treated soil is not available. Therefore, in this paper, an experimentally validated theoretical model to predict erosion in terms of the effective shear-strength parameters is described.

\section{Theoretical Development}

\section{Mechanism of Particle Detachment for Erosion}

The detachment mechanism of individual particles from the soil bed under applied hydrodynamic forces is important in formulating the process of erosion. Several studies were conducted to determine the mechanism of particle detachment, such as rolling or sliding (Hubbe 1985; Sharma et al. 1992; Reddi and Bonala 1997; Briaud et al. 2001; Middleton and Southard 1978). Hubbe (1985) carried out coaxial shearing tests for uniform colloidal titanium dioxide $\left(\mathrm{TiO}_{2}\right)$ spheres to determine the critical mechanism of particle detachment from rough surfaces and concluded that the mechanism was by rolling when the hydrodynamic force applied to the sphere exceeded a critical value. Sharma et al. (1992) conducted centrifuge and flow experiments for $10-\mu \mathrm{m}$ particles of glass and $40-\mu \mathrm{m}$ particles of polystyrene and concluded that the particles were released from surfaces by rolling, rather than by sliding or lifting. This concept was implemented by Reddi and Bonala (1997), who used the rolling mechanism to correlate the interparticle bond strength with the hydrodynamic force applied to a particle. Briaud et al. (2001) derived equations for critical shear stress initiating erosion considering sliding and rolling of particles separately and compared them with

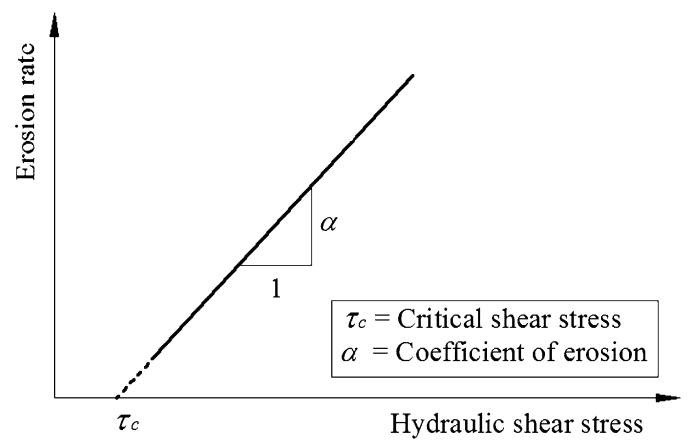

Fig. 1. Typical variation of erosion rate with hydraulic shear stress the Erosion Function Apparatus (EFA) test results. They concluded that sliding was not the eroding mechanism, or at least, not the only mechanism. However, EFA was used to study the scour rate under bridge piers by applying a flow velocity of $0.1-6 \mathrm{~m} / \mathrm{s}$, which was a much higher value to apply in internal crack erosion. A more relevant application of this rolling mechanism can be found in Middleton and Southard (1978).

In this study, the commencement of movement of an average grain has been formulated, assuming that it will begin to move by rotating about a pivot provided by contact with other grains. Thus, the theoretical model considers rolling to be the mechanism by which particles are detached from the soil bed because of hydrodynamic forces. When the hydrodynamic forces placed on chemically bonded grains exceed a critical value, the interparticle bonds are broken, and the grains become suspended. These suspended particles are then transported by the eroding fluid, which completes the process of erosion. The energy required by the particles to erode should be equal to the energy dissipated by the excess hydraulic shear stress during erosion. This energy required by the particles to erode is the sum of the energy required to break the interparticle bonds and the energy required to bring the particle into full suspension reaching flow velocity, assuming no resettlement occurs once the particles are fully suspended.

The erosion model described is based on the energy conservation principle, and the formulation of the aforementioned components is explained in the following.

\section{Energy Required to Break the Interparticle Bonds}

Figs. 2 and 3 describe the average and actual failure surfaces, and the applied and resistance forces on a single interparticle bond under plane shear, respectively. As shown in Fig. $3, F_{n i}$ (Newtons) is the applied normal force, $F_{s i}$ (Newtons) is the applied shear force because of shearing, $S_{i}$ (Newtons) is the mobilized shearing resistance along the failure surface, $N_{i}$ (Newtons) is the mobilized normal resistance at the contact point, $\delta x_{i}$ (meters) and $\delta y_{i}$ (meters) are the displacements of $i$ th contact along and normal to the average failure surface, respectively, $\delta d_{i}$ (meters) is the displacement along the failure surface of $i$ th contact, $n$ (per meters squared) is the number of interparticle bonds in a unit surface area, $\sigma_{n}^{\prime}$ (Pascals) is the applied effective normal stress, $\tau^{\prime}$ (Pascals) is the measured shear resistance, and $d_{s}$ (meters) is the measured shear displacement.

In the process of plane shear failure, one can consider that two steps are involved: (1) breaking the interparticle bonds; and (2) overcoming the frictional resistance. Therefore, the total work done by the applied normal and shear forces will include the energy required to break the interparticle bonds and for overcoming the frictional resistance.

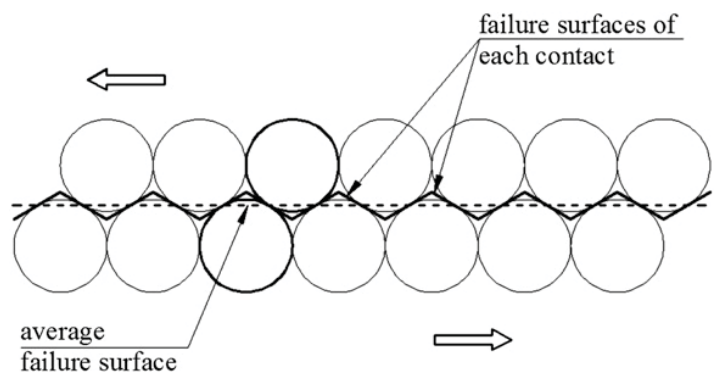

Fig. 2. Failure surface of a specimen under plane shearing 
If the energy required for breaking the $i$ th interparticle bond is taken as $E_{b i}$ (Joules), then

$$
F_{s i} \delta x_{i}-F_{n i} \delta y_{i}=\delta E_{b i}+F_{i} \delta d_{i}
$$

where $F_{i}$ (Newtons) $=$ frictional resistance between the soil grains. Once the interparticle bond is broken, the particles can be considered as having no cohesion, and the frictional resistance can be expressed by eliminating the cohesive term as

$$
F_{i}=\mu_{i}\left(F_{n i} \cos \beta+F_{s i} \sin \beta\right)
$$

where $\mu_{i}=$ coefficient of friction between particles; and $\beta$ (degrees) $=$ angle of the reference particle to the vertical with respect to the contact particle. Substituting Eq. (2) in Eq. (1) and considering the forces and deformation vectors in Fig. 3, $\delta E_{b i}$ can be given as

$$
\delta E_{b i}=\left[\tau^{\prime}\left(1-\mu_{i} \tan \beta\right)-\sigma_{n}^{\prime}\left(\tan \beta+\mu_{i}\right)\right] \frac{\delta d_{s}}{n}
$$

Replacing the infinitesimal increments by the appropriate differential increments, and then integrating in the range $E_{b i}$ from 0 to $E_{b i}$ and $d_{s}$ from 0 to $d_{s f}$, the energy required to break a single interparticle bond is then given by

$$
E_{b i}=\frac{1}{n}\left\{\left[\int_{0}^{d_{s f}} \tau^{\prime} d\left(d_{s}\right)\right]\left(1-\mu_{i} \tan \beta\right)-\sigma_{n}^{\prime}\left(\tan \beta+\mu_{i}\right) d_{s f}\right\}
$$

where $d_{s f}$ (meters) $=$ measured shear displacement at failure along the average shear surface. The average number of contacts $\left(k^{\prime}\right)$ per particle can now be expressed as

$$
k^{\prime}=n A_{e p}
$$

In Eq. (5), $A_{e p}$ (meters squared) is the effective area per particle in the shear surface that can be expressed as $q D^{2}$, where $q$ is a constant that depends on the packing arrangement of particles, and $D$ (meters) is the mean particle diameter. Now the energy required for one particle of soil to break the interparticle bonds $\left(E_{b}\right)$ can be obtained by multiplying $E_{b i}$ by $k^{\prime}$ as

$$
E_{b}=q D^{2}\left\{\left[\int_{0}^{d_{s f}} \tau^{\prime} d\left(d_{s}\right)\right]\left(1-\mu_{i} \tan \beta\right)-\sigma_{n}^{\prime}\left(\tan \beta+\mu_{i}\right) d_{s f}\right\}
$$

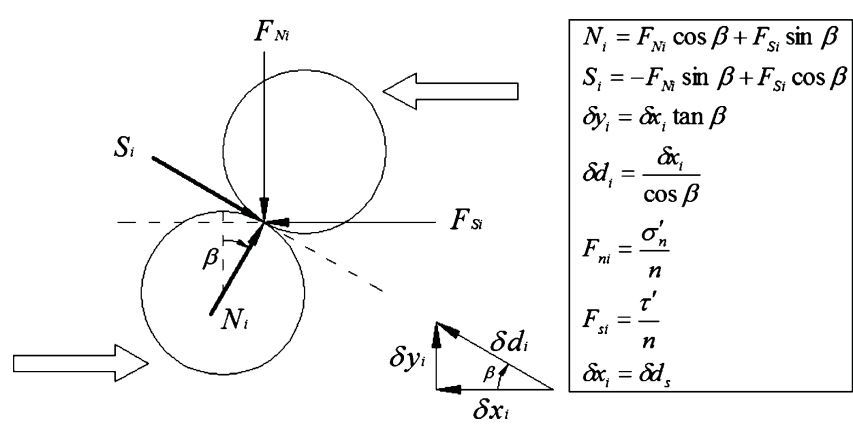

Fig. 3. Definition of applied forces, resistant forces, and deformations of two particles at contact point $i$ under plane shearing
Bishop (1954) developed a correlation between $\phi$ and $\mu$ based on shear box testing conducted on granular materials, and proposed

$$
\mu=\frac{2}{3} \sin \phi
$$

where $\phi$ (degrees) $=$ angle of the internal friction of soil. Then, after converting the shear displacement into shear strain, Eq. (6) leads to

$$
\begin{aligned}
E_{b}=q D^{2} \frac{h_{0}}{100} & \left\{\left[\int_{0}^{\gamma_{f}} \tau^{\prime} d(\gamma)\right]\left(1-\frac{2}{3} \sin \phi^{\prime} \tan \beta\right)\right. \\
& \left.-\sigma_{n}^{\prime}\left(\tan \beta+\frac{2}{3} \sin \phi^{\prime}\right) \gamma_{f}\right\}
\end{aligned}
$$

where $h_{0}$ (meters) $=$ initial height of the specimen that undergoes direct shear; $\gamma$ (percent) $=$ shear strain; and $\gamma_{f}$ (percent) $=$ shear strain at failure. The term $\int_{0}^{\gamma_{f}} \tau^{\prime} d(\gamma)$ in Eq. (8) is the strain energy per unit volume because of shearing (area under the shear stress-strain curve) up to the failure shown in Fig. 4, obtained from shear box tests under a given effective normal stress $\left(\sigma_{n}^{\prime}\right)$. The erosion tests were conducted without any effective normal stress on the soil surface, which ensured real-field conditions. Therefore, it is important to calculate $E_{b}$ also for the condition of zero effective normal stress. For this purpose, the strain energy per unit volume up to peak strength for $\sigma{ }_{n}=0$ can be predicted from the experimental results, whereas the normal stress term in Eq. (8) is set to zero. Therefore

$$
E_{b}=q D^{2} \frac{h_{0}}{100}\left\{\left[\int_{0}^{\gamma_{f}} \tau^{\prime} d(\gamma)\right]_{\left(\sigma_{n}^{\prime}=0\right)}\left(1-\frac{2}{3} \sin \phi^{\prime} \tan \beta\right)\right\}
$$

The preceding term will be affected by chemical treatment, and it is postulated that the shaded area under the curve (Fig. 4) will be increased. Subsequently, the energy required by a single grain of soil to break the interparticle bonds after stabilization can be expressed by

$$
E_{b}^{*}=q D^{2} \frac{h_{0}}{100}\left\{\left[\int_{0}^{\gamma_{f}} \tau^{\prime} d(\gamma)\right]_{\left(\sigma_{n}^{\prime}=0\right)}^{*}\left(1-\frac{2}{3} \sin \phi^{\prime *} \tan \beta\right)\right\}
$$

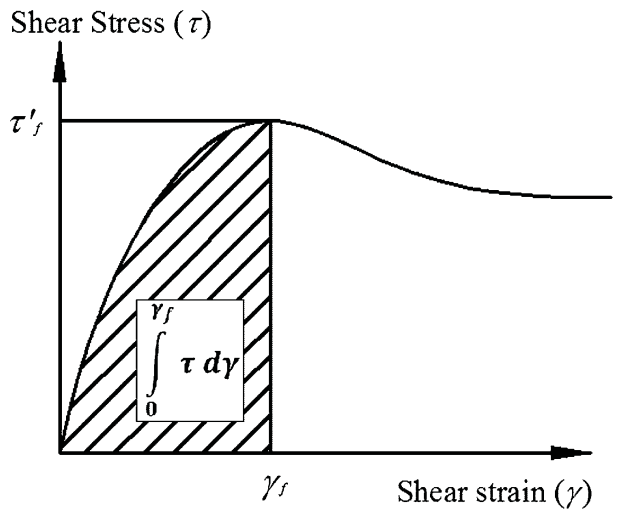

Fig. 4. Strain energy per unit volume because of shearing up to failure under $\sigma_{n}^{\prime}$ 


\section{Energy Required to Bring the Particles into Suspension}

The energy required for a particle to become suspended is formulated by considering its movement as two distinct processes. First, it will roll on the contact particle until contact is lost, and then it will lift while moving with the fluid flow until it attains the same velocity as the fluid flow.

Energy Required for a Particle to Roll on the Contact Particle As illustrated in Fig. 5, a particle located at an angle of $\theta$ (degrees) from the vertical plane through the axis of crack is considered to be the reference particle. The velocities and the forces acting on the reference particle in the $X$ - $X$ plane (Fig. 5) along the crack are shown in Fig. 6. Because of the moment around the contact point developed by the drag force $\left(F_{D}\right)$ (Newtons), lift force $\left(F_{L}\right)$ (Newtons), and the weight component of the grain normal to the soil bed $\left(W_{S} \cos \theta\right)$ (Newtons), the particle is forced to roll on the surface of the contact particle beneath it with an angular velocity of $\omega_{p}$ (radians per second) around its center $\left(O^{\prime}\right) . N_{F}$ (Newtons) and $F_{F}$ (Newtons) are the normal and friction forces, respectively, acting at the contact point, $\psi$ (degrees) is the angle by which the reference particle has rolled, and $m$ (kilograms) is the mass of the soil grain. The linear velocities of the particle in the tangential and radial directions can be written as $V_{t}$ (meters per second) and $V_{r}$ (meters per second ), respectively. Because the radius of the rolling path is assumed to be constant, $V_{r}=0$; hence, acceleration in the radial direction (meters per seconds squared) is $a_{r}=0$. Considering the equations of motion in radial and tangential directions, and for angular motion, $V_{t}$ can be obtained as

$$
\begin{aligned}
V_{t}^{2}=\frac{5 D}{7 m}\left\{F_{D}[\psi+\sin \beta-\sin (\beta-\psi)]\right. \\
\left.+\left(W_{S} \cos \theta-F_{L}\right)[\cos \beta-\cos (\beta-\psi)]\right\}
\end{aligned}
$$

At the instant when $\psi=\psi_{\max }$, the moving particle leaves the contact surface of the other particle, and $N_{F}=0$. Therefore, solving the equation of motion for the radial direction gives the value of $\psi_{\max }$ as

$$
\psi_{\max }=\tan ^{-1}\left[\frac{\left(W_{S} \cos \theta-F_{L}\right)}{F_{D}}\right]+\beta
$$

From the principles of work and energy, assuming there is no kinetic energy at $\psi=0$, the work done $\left(W D_{R}\right)$ (Joules) in rolling the particle on the contact particle is given by

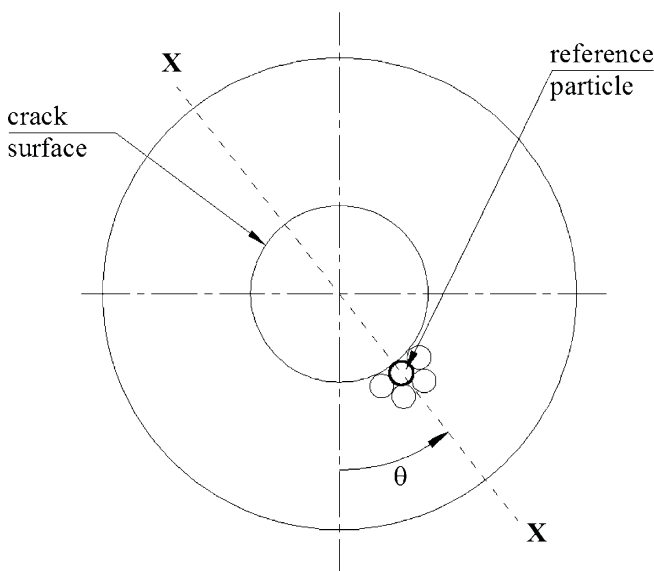

Fig. 5. The position of the reference particle inside the crack

$$
W D_{R}=\frac{1}{2}\left(m V_{t}^{2}+I_{G} \omega_{p}^{2}\right)
$$

where $I_{G}$ (kilograms per square meters) $=$ moment of inertia of the soil grain about its center of gravity. In the preceding, the values of $V_{t}$ and $\omega_{p}$ should be at $\psi=\psi_{\max }$, and hence, Eq. (13) yields

$$
W D_{R}=\frac{7}{10} m\left[V_{t}^{2}\right]_{\left(\psi=\psi_{\max }\right)}
$$

\section{Energy Required for a Particle to be Suspended}

After completing the process of rolling as previously described, the soil particle will be suspended in the water flow and will attain the same flow velocity. The work done by fluid flow on the particle to bring it into suspension is formulated in this section. The forces and velocities acting on the soil grain are presented in Fig. 7. When the soil particle has attained its full suspension state, it is assumed that it obtains the same flow velocity $\left(V_{f}\right)$ (meters per second). Consequently, the drag force becomes zero. Also, the vertical velocity will be zero if the particle is assumed to move along with lateral flow, and the lift force will balance the submerged weight of the particle. For the convenience of formulation, it is assumed that the magnitude of the drag force will change linearly from $F_{D(\max )}$ to 0 , and also the lift force will vary linearly from $F_{L(\max )}$ to $W_{S} \cos \theta$, when the particle transfers from the soil bed to a state of suspension. To formulate the work done in this process, applying the equations of motion $S_{p}$ (meters) and $S_{n}$ (meters), the distances traveled by the particle in parallel and normal directions to the soil bed, respectively, can be found as

$$
S_{p(\max )}=\frac{m}{F_{D(\max )}}\left(V_{f}^{2}-V_{p(0)^{2}}\right)
$$

where $V_{p(0)}($ meters per second $)=$ velocity of the grain in the parallel direction at $S_{p}=0$ and

$$
S_{n(\max )}=\frac{m}{\left(W_{S} \cos \theta-F_{L(\max )}\right)} V_{n(0)}{ }^{2}
$$

where $V_{n(0)}$ (meters per second $)=$ velocity of the grain in the normal direction at $S_{n}=0$. The work done $\left(W D_{S}\right)$ (Joules) in bringing the particle into suspension is given by

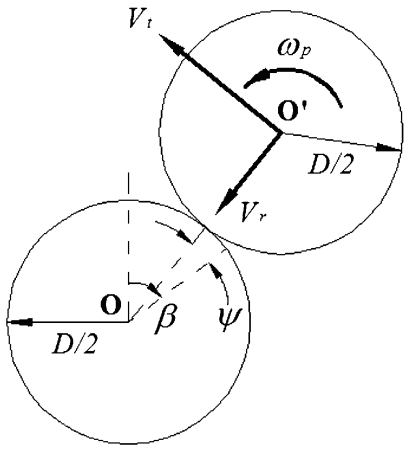

(a)

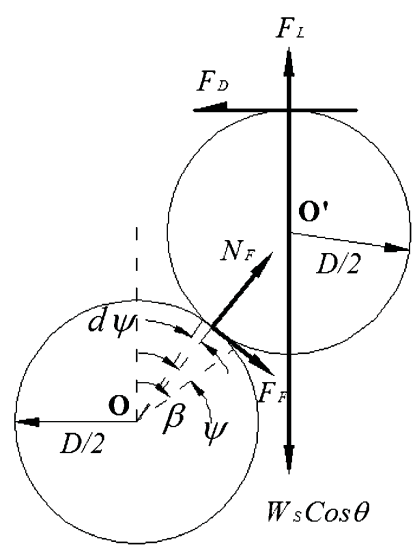

(b)

Fig. 6. (a) Velocities and (b) forces acting on the reference particle 


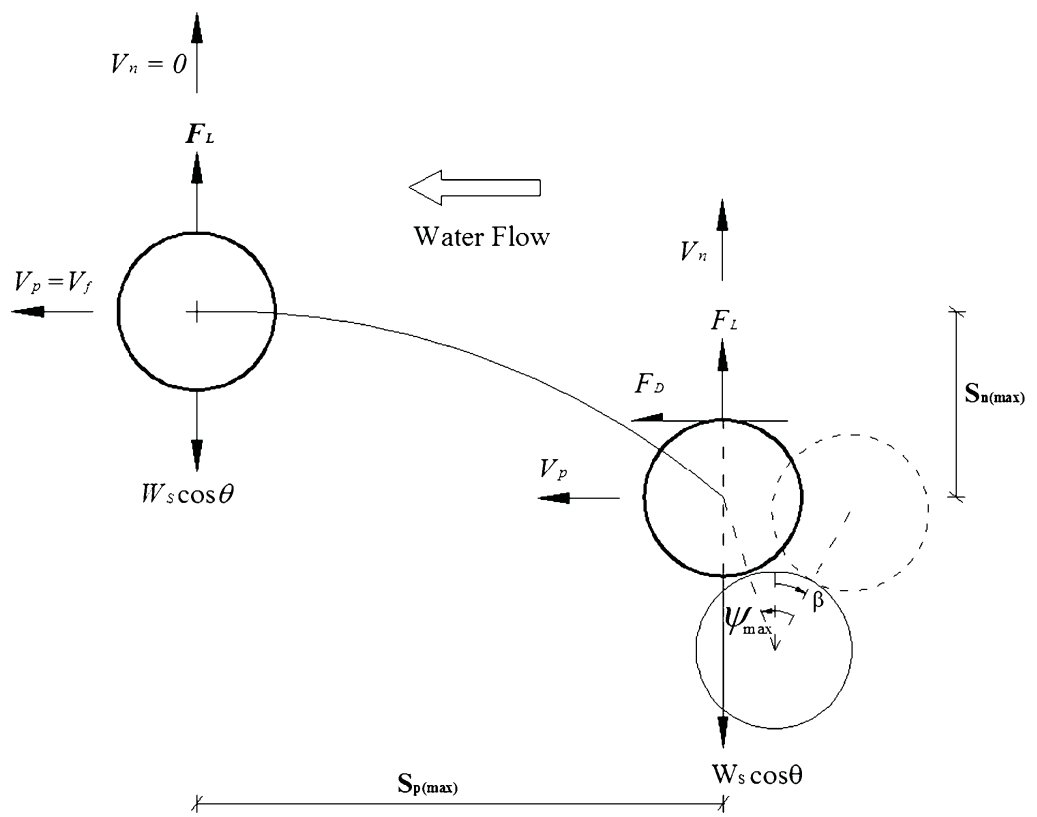

Fig. 7. Forces and velocities acting on the particles at the beginning and end of the suspension process

$$
W D_{S}=\frac{m}{2}\left[V_{f}^{2}-V_{p(0)}^{2}-V_{n(0)}^{2}\right]
$$

$V_{p(0)}$ and $V_{n(0)}$ can be related to the tangential velocity $\left(V_{t}\right)$ of the particle at $\psi=\psi_{\max }$ and can be substituted into Eq. (17) to obtain $W D_{S}$ as

$$
W D_{S}=\frac{m}{2}\left\{V_{f}^{2}-\left[V_{t}^{2}\right]_{\left(\psi=\psi_{\max }\right)}\right\}
$$

The total energy $\left(E_{\theta}^{*}\right)$ required for a single stabilized particle of soil to be eroded is

$$
E_{\theta}^{*}=E_{b}^{*}+W D_{R}+W D_{S}
$$

\section{Formulating the Rate of Erosion}

Fig. 8 shows the change in the radius of the crack of a specimen subjected to erosion test by $d r_{t}$ at a time interval of $d t$. It is assumed here that the radius of the crack changes linearly over time and that erosion is uniform over the surface of the crack. Using weightvolume relationships, the number of particles $(N)$ in a unit volume can be expressed by

$$
N=\frac{6 \rho_{d}}{G_{s} \rho_{w} \pi D^{3}}
$$

where $\rho_{d}$ (kilograms per cubic meter) $=$ dry density of the soil; $G_{s}=$ specific gravity of soil; and $\rho_{w}$ (kilograms per cubic meter) $=$ density of water. If the energy required to erode a single particle at an angle $\theta$ is denoted by $E_{\theta}^{*}$ [Eq. (19)], then the total energy $\left(E_{d v}\right)$ (Joule) required to erode an infinitesimally small volume $(d v)$ of soil at an angle of $\theta$ (as shown in Fig. 8) is given by

$$
E_{d v}=E_{\theta}^{*} \times \frac{6 \rho_{d}}{G_{s} \rho_{w} \pi D^{3}} r_{t} d \theta d r_{t} l
$$

where $r_{t}$ (meters) $=$ radius of the crack at time $t$ (seconds); and $l$ (meters) $=$ length of the crack.

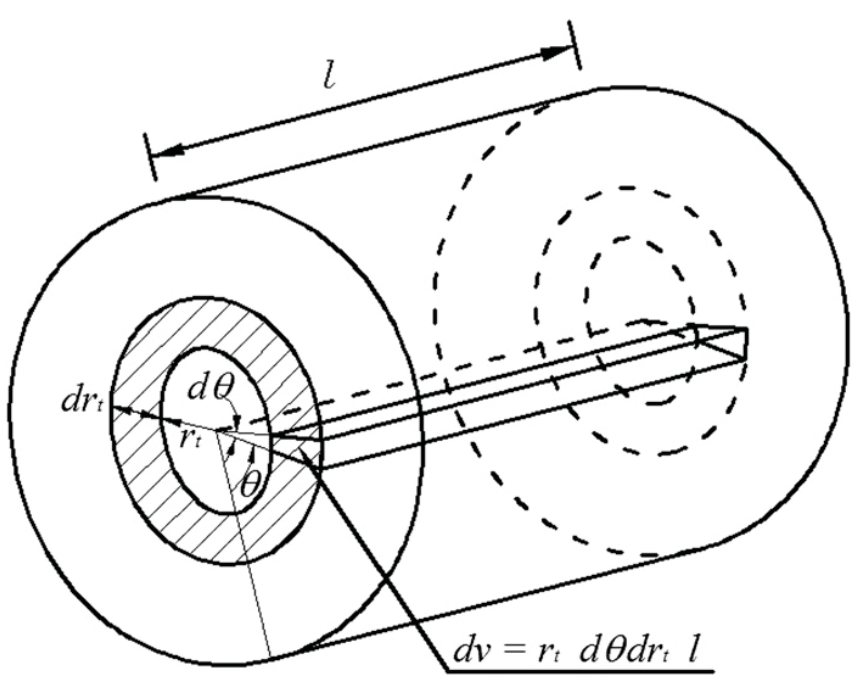

Fig. 8. Change in crack radius of test specimen caused by erosion

From Eq. (21), the total energy $\left(E_{T}\right)$ required for erosion in time $d t$ can be calculated by

$$
E_{T}=\frac{12 \rho_{d}}{G_{s} \rho_{w} \pi D^{3}} r_{t} d r_{t} l \int_{0}^{\pi} E_{\theta}^{*} d \theta
$$

The energy dissipated by excess hydraulic shear stress $\left(\Delta E^{\prime}\right)$ during erosion over time dt was given by Muttuvel (2008) as

$$
\Delta E^{\prime}=\omega\left(\tau_{a}-\tau_{c}\right) V_{f} 2 \pi r_{t} l d t
$$

where $\omega=$ efficiency factor used to capture the energy loss because of heat and noise; $\tau_{a}$ (Pascals) $=$ hydraulic shear stress applied; and $\tau_{c}$ 
(Pascals $)=$ critical shear stress that commences erosion. According to the conservation of energy, the energy dissipated by excess hydraulic shear stress during erosion should be equal to the energy taken by the particles for erosion. Therefore, from Eqs. (22) and (23)

$$
\frac{d r_{t}}{d t}=\frac{\pi^{2} D^{3} G_{s} \rho_{w}}{6 \rho_{d} \int_{0}^{\pi} E_{\theta}^{*} d \theta} \times \omega\left(\tau_{a}-\tau_{c}\right) V_{f}
$$

The rate of erosion $(\dot{\varepsilon})$ (kilograms per square meters per second), that is, the amount of soil eroded in unit time over a unit surface area, can now be written by multiplying $d r_{t} / d t$ by dry density as

$$
\dot{\varepsilon}=\frac{\pi^{2} D^{3} G_{s} \rho_{w}}{6 \int_{0}^{\pi} E_{\theta}^{*} d \theta} \times \omega\left(\tau_{a}-\tau_{c}\right) V_{f}
$$

The denominator term in Eq. (25) can be obtained by substituting for $E_{\theta}^{*}$ from Eq. (19) and integrating, at $\psi=\psi_{\max }$, as

$$
\begin{aligned}
\int_{0}^{\pi} E_{\theta}^{*} d \theta= & q \pi D^{2} \frac{h_{0}}{100}\left\{\left[\int_{0}^{\gamma_{f}} \tau^{\prime} d(\gamma)\right]_{\left(\sigma_{n}^{\prime}=0\right)}^{*}\left(1-\frac{2}{3} \sin \phi^{\prime *} \tan \beta\right)\right\} \\
& +\frac{m}{2} \pi V_{f}^{2}+\frac{D}{7}\left[F_{D} \times \int_{0}^{\pi} \arctan \left(\frac{W_{S} \cos \theta-F_{L}}{F_{D}}\right) d \theta\right. \\
& \left.+\pi F_{D}(\beta+\sin \beta)-\pi F_{L} \cos \beta\right]
\end{aligned}
$$

The drag and lift forces acting on a soil particle are from the resultant of both pressure and friction from the fluid flow. When considering water flow over a compacted bed of flat soil, the particles are not fully exposed to the flow because of other surrounding particles. Therefore, the water flow would mainly influence the top surface of the particles, where the bed of soil is considered to be a flat surface. The drag force caused by a parallel flow of fluid over a flat surface is totally derived from frictional drag, because the pressure drag is zero. This force caused by friction over a unit surface is the applied wall shear stress $\tau_{a}$, and the total drag force $F_{D}$ on the particle can be written as $q D^{2} \tau_{a}$. Substituting for $F_{D}$ and rearranging Eq. (26) gives

$$
\begin{aligned}
\int_{0}^{\pi} E_{\theta}^{*} d \theta= & q D^{2} \frac{h_{0}}{100}\left\{\left[\int_{0}^{\gamma_{f}} \tau^{\prime} d(\gamma)\right]_{\left(\sigma_{n}^{\prime}=0\right)}^{*}\left(1-\frac{2}{3} \sin \phi^{\prime *} \tan \beta\right)\right\} \\
+ & \frac{\pi^{2} D^{3} G_{s} \rho_{w}}{12} V_{f}^{2} \\
+ & \frac{q D^{3} \tau_{a}}{7}\left\{\int_{0}^{\pi} \arctan \left[\frac{\left(G_{S}-1\right) \rho_{w} g \pi D}{6 q \tau_{a}} \cos \theta-x\right] d \theta\right. \\
& +\pi(\beta+\sin \beta)-x \pi \cos \beta\}
\end{aligned}
$$

where $g$ (meters per seconds squared) $=$ gravitational acceleration; and $x=$ ratio of lift force to drag force. The integration term in Eq. (27) can be solved using the trapezium rule (James 2010). For this purpose, it can be taken as the area under the curve

$$
f(\theta)=\arctan \left[\frac{\left(G_{S}-1\right) \rho_{w} g \pi D}{6 q \tau_{a}} \cos \theta-x\right]
$$

in the region from $\theta=0$ to $\theta=\pi$. To simplify Eq. (27), the term $B$ is introduced, where

$$
B=\int_{0}^{\pi} f(\theta) d \theta
$$

For further simplification of Eq. (27), the term $A^{*}$ is introduced, where

$$
A^{*}=\frac{h_{0}}{100}\left[\int_{0}^{\gamma_{f}} \tau^{\prime} d(\gamma)\right]_{\left(\sigma_{n}^{\prime}=0\right)}^{*}
$$

Eq. (27) can now be rewritten as

$$
\begin{gathered}
\int_{0}^{\pi} E_{\theta}^{*} d \theta=\pi^{2} D^{3}\left\{\frac{q}{\pi D}\left[A^{*}\left(1-\frac{2}{3} \sin \phi^{\prime *} \tan \beta\right)\right]+\frac{G_{s} \rho_{w}}{12} V_{f}^{2}\right. \\
\left.+\frac{q \tau_{a}}{7 \pi^{2}}[B+\pi(\beta \sin \beta)-x \pi \cos \beta]\right\}
\end{gathered}
$$

Finally, substituting Eq. (30) into Eq. (25), the rate of erosion $(\dot{\varepsilon})^{*}$ for the treated soil can be written as

$$
(\dot{\varepsilon})^{*}=\frac{G_{S} \rho_{w} \omega V_{f}\left(\tau_{a}-\tau_{c}^{*}\right)}{6\left\{\frac{q}{\pi D}\left[A^{*}\left(1-\frac{2}{3} \sin \phi^{\prime *} \tan \beta\right)\right]+\frac{G_{s} \rho_{w}}{12} V_{f}^{2}+\frac{q \tau_{a}}{7 \pi^{2}}[B+\pi(\beta \sin \beta)-x \pi \cos \beta]\right\}}
$$

Eq. (31) can also be written in the form of the linear relationship between the excess hydraulic shear stress and erosion rate as (Arulanandan et al. 1975; Sargunan 1976)

$$
(\dot{\varepsilon})^{*}=\alpha^{*}\left(\tau_{a}-\tau_{c}^{*}\right)
$$

where the coefficient of erosion $\alpha^{*}$, of the treated soil then becomes

$$
\alpha^{*}=\frac{G_{S} \rho_{w} \omega V_{f}}{6\left\{\frac{q}{\pi D}\left[A^{*}\left(1-\frac{2}{3} \sin \phi^{\prime *} \tan \beta\right)\right]+\frac{G_{s} \rho_{w}}{12} V_{f}^{2}+\frac{q \tau_{a}}{7 \pi^{2}}[B+\pi(\beta \sin \beta)-x \pi \cos \beta]\right\}}
$$




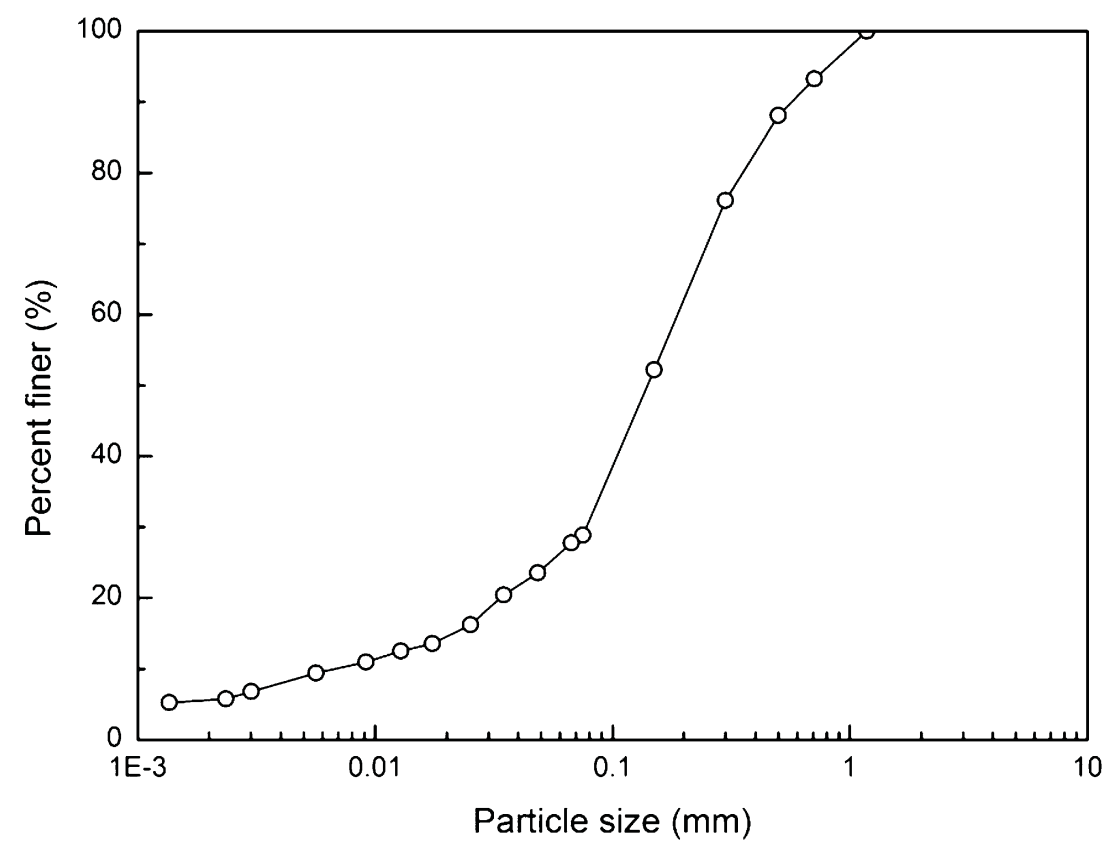

Fig. 9. Particle size distribution of Wombeyan caves silty sand

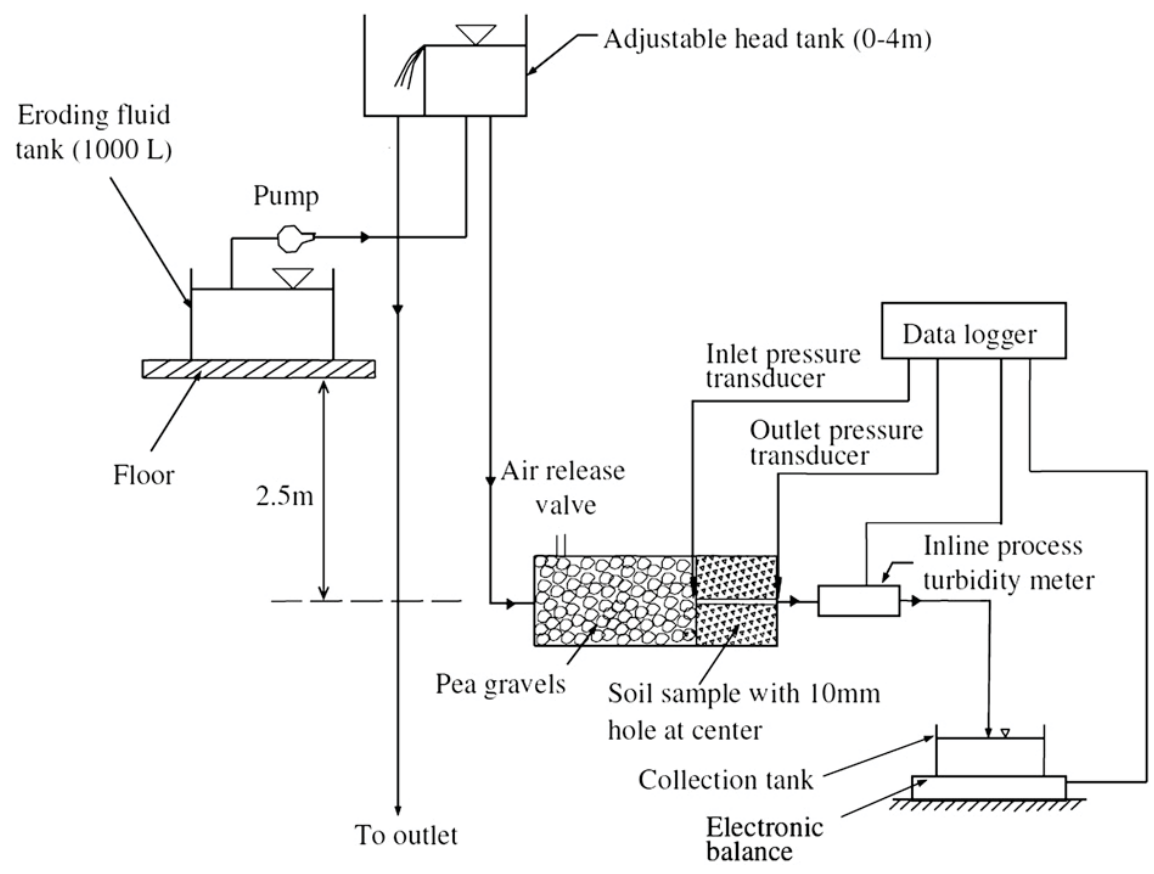

Fig. 10. Schematic diagram of PSAICE [Indraratna et al. (2008b), ( ) ASCE]

\section{Experimental Investigation}

\section{Shear Tests}

\section{Type of Soil and Stabilizer Used}

A series of standard direct-shear tests were conducted to obtain the stress-strain behavior of chemically treated and untreated erodible silty sand (SM). The soil used for this study was collected from Wombeyan caves in New South Wales, Australia and classified as SM according to the Unified Soil Classification System (USCS). The soil is nonplastic, with a liquid limit of $22.5 \%$ and a specific gravity of 2.67. The particle size distribution of this soil is shown in Fig. 9. According to the standard Proctor compaction test, the silty sand has a maximum dry density (MDD) of $1,838 \mathrm{~kg} / \mathrm{m}^{3}$, which corresponds to the optimum moisture content (OMC) of $11.6 \%$. From the standard pinhole tests (Australian Standards 1997), this silty sand is classified as a highly erodible soil (D1). The percent dispersion (PD) calculated from the percent dispersion test (Australian Standards 2008) is 44\%. 

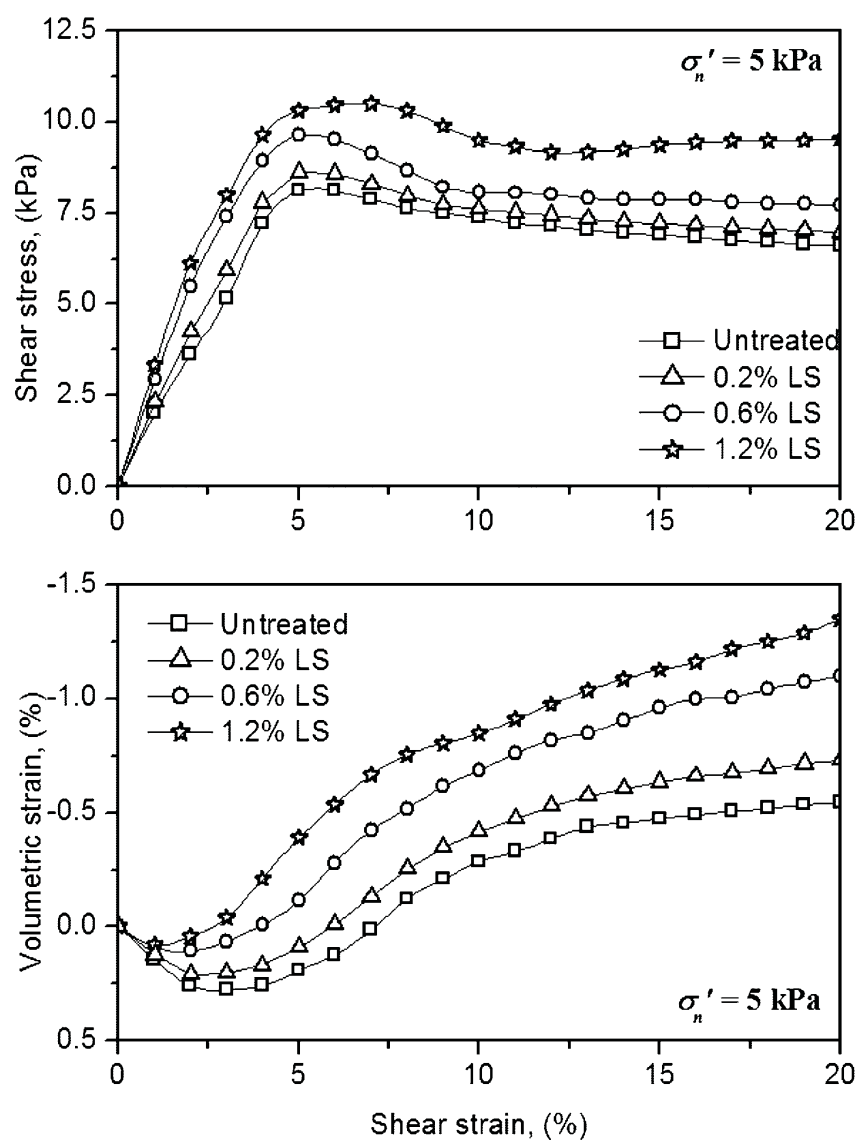

Fig. 11. Effect of LS treatment on the shear behavior under $15 \mathrm{kPa}$ of normal stress

Lignosulfonate (LS) is a by-product of paper and timber industry, and it was used as the chemical stabilizer. Karol (2003) described it as a dark brown inflammable liquid that smells like vanilla. Compared with other traditional and nontraditional chemical admixtures, LS is cheaper, environmentally friendly, nonhazardous, and does not appreciably change the $\mathrm{pH}$ level of the soil after treatment (Muttuvel 2008).

\section{Procedure and Test Plan}

Treated soil specimens for shear tests were prepared using three dosages $(0.2,0.6$, and $1.2 \%)$ of LS by dry soil weight. The required amount of stabilizer was first added with an additional amount of water needed to achieve the optimum moisture content before mixing with the soil. The sample was then statically compacted to 95\% MDD using a specially made mold. Ninety-five percent MDD was selected for this study because the recommended field compaction level for most practical applications is $95-100 \%$ MDD. The compacted specimens were wrapped in moisture proof bags and cured for 7 days, and then saturated with eroding fluid (water) inside the sample container of the direct-shear box for $24 \mathrm{~h}$. The normal stresses selected were $5,10,15$, and $22 \mathrm{kPa}$. These relatively low normal stresses represent typical erosion at shallow depths. Each specimen was then subjected to drained direct-shear testing under a constant shearing rate of $0.05 \mathrm{~mm} / \mathrm{min}$.

\section{Erosion Tests}

The experiments to measure the erosion rate of soil treated with LS at different hydraulic gradients were conducted using the PSAICE

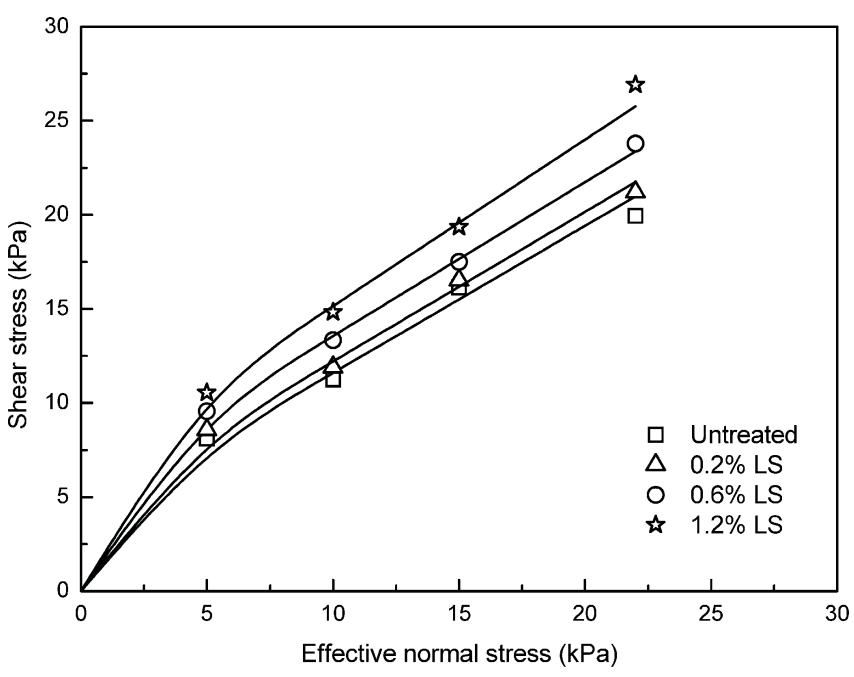

Fig. 12. Failure envelopes of LS-treated and -untreated silty sand

Table 1. Peak Friction Angle, Secant Shear Modulus, and Maximum Dilation Angle for Untreated and Treated Silty Sand in Direct Shear Tests

\begin{tabular}{lccc}
\hline $\begin{array}{l}\text { Amount } \\
\text { of LS }(\%)\end{array}$ & $\begin{array}{c}\text { Peak friction } \\
\text { angle (deg) at } \\
\text { linear region }\end{array}$ & $\begin{array}{c}\text { Secant shear } \\
\text { modulus }(\mathrm{kPa}) \text { at } \\
2.5 \% \text { shear strain }\end{array}$ & $\begin{array}{c}\text { Maximum } \\
\text { dilation angle } \\
(\mathrm{deg})\left(\sigma_{n}^{\prime}<5 \mathrm{kPa}\right)\end{array}$ \\
\hline 0 & 38.00 & $173.96-429.60$ & 5.09 \\
0.2 & 38.46 & $203.13-433.22$ & 6.92 \\
0.6 & 39.28 & $258.32-440.46$ & 8.70 \\
1.2 & 41.51 & $214.45-467.52$ & 9.98 \\
\hline
\end{tabular}

designed and built at the University of Wollongong. A schematic diagram of the apparatus (Fig. 10) shows the soil specimen with a 10mm-diameter coaxial hole (i.e., simulated crack). This equipment consists of a storage tank with a capacity of $1 \mathrm{~m}^{3}$ to supply eroding fluid and an adjustable head tank to provide the required hydraulic gradient (maximum 40). The pressure transducers connected to the sample container measure the pressure difference across the crack. To monitor the effluent turbidity continuously, an inline process turbidity meter is connected to downstream of the sample. This measured turbidity can be converted into erosion rate using the relationship between soil concentration (kilogram per cubic meter) and turbidity (nephelometric turbidity units [NTU]) developed by Indraratna et al. (2008b). The effluent is collected to a specially designed electronic balance to measure the continuous flow rate through the crack. The testing procedure and the calculations are described in detail elsewhere by Indraratna et al. (2008b).

\section{Results and Discussion}

\section{Stress-Strain Behavior}

The observed stress-strain behavior of LS-treated and -untreated specimens under $5 \mathrm{kPa}$ of effective normal stress is illustrated in Fig. 11. The peak strength and initial stiffness increased moderately with the percentage of LS, and with stabilization, the volumetric response became less compressive in the early stages of shearing and more expansive thereafter. The maximum angle of dilation that occurred around the peak strength increased with LS treatment. The peak strength envelopes shown in Fig. 12 and the data presented in 


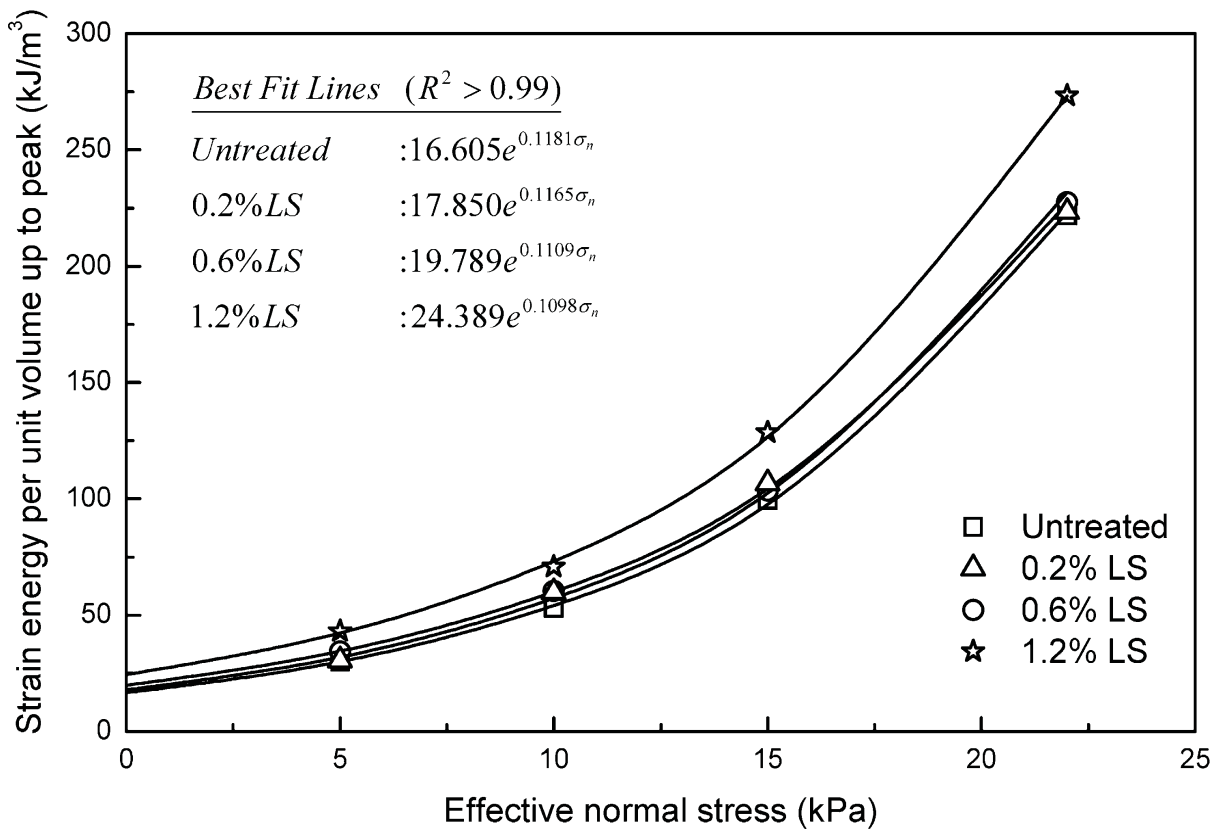

Fig. 13. Strain energy per unit volume up to peak calculated from stress-strain curves with effective normal stress for treated and untreated silty sand

Table 1 provided further analysis of the shear behavior of untreated silty sand and silty sand treated with LS. The peak friction angle at the linear region of failure envelopes increased slightly from $38^{\circ}$ for untreated soil to $41.5^{\circ}$ for soil treated with $1.2 \% \mathrm{LS}$. The secant shear modulus values were calculated at $2.5 \%$ shear strain, because that was the maximum shear strain within which all the stress-strain curves were linear. Because of LS treatment, the shear modulus of specimens under $5 \mathrm{kPa}$ rose from 174 to $214.45 \mathrm{kPa}$ and from 429.60 to $467.52 \mathrm{kPa}$ under $22-\mathrm{kPa}$ effective normal stresses. In addition, the maximum angle of dilation of specimens of treated soil under $5 \mathrm{kPa}$ of effective normal stress rose from 5.09 to $9.98^{\circ}$, attributed to LS treatment.

\section{Model Parameters}

To validate Eq. (31) and calculate the rate of erosion of LS stabilized soil, the strain energy per unit volume (i.e., area under the stressstrain curve) up to peak stress under zero effective normal stress should be used. For this purpose, the corresponding areas under the stress-strain curves were calculated and plotted against the effective normal stress (Fig. 13). It was evident that the strain energy per unit volume increased as a result of LS treatment of all the normal stresses considered here. Then, the strain energy per unit volume at zero effective normal stress values was predicted from Fig. 13 through best-fit lines drawn for the laboratory data for untreated, and 0.2, 0.6, and $1.2 \%$ LS-treated soil, and the corresponding values of $A^{*}$ [Eq. (29)] were calculated and given in Table 2. The input data used to find the model parameters are summarized in Table 3 . The values of $\phi^{* \prime}$ were from the shear test results, and $\alpha *$ was determined from the results of the erosion tests given earlier by Indraratna et al. (2008b) as the slopes of erosion plots. It is clear from Table 3 that the values of $A^{*}$ and internal friction angle $\left(\phi^{* \prime}\right)$ at zero normal stress increased, whereas the coefficient of soil erosion $\left(\alpha^{*}\right)$ decreased because of LS treatment.

By rearranging Eq. (33), the efficiency factor $(\omega)$ can be simplified to
Table 2. Strain Energy per Unit Volume up to Peak at Zero Effective Normal Stress for Silty Sand Treated with LS

\begin{tabular}{lcr}
\hline Amount of LS (\%) & {$\left[\int_{0}^{\gamma_{f}} \tau d \gamma\right]_{\sigma_{n}^{\prime}=0}\left(\mathrm{~kJ} / \mathrm{m}^{3}\right)$} & $A^{*}\left(\mathrm{~J} / \mathrm{m}^{2}\right)$ \\
\hline 0 & 16.605 & 4.151 \\
0.2 & 17.850 & 4.463 \\
0.6 & 19.789 & 4.947 \\
1.2 & 24.389 & 6.097 \\
\hline
\end{tabular}

Table 3. Experimental Data Used in Parameter Calculations

\begin{tabular}{lccccc}
\hline & \multicolumn{2}{c}{ Present Study } & & \multicolumn{2}{c}{ Indraratna et al. (2008b) } \\
\cline { 2 - 3 } LS & $A^{*}$ & $\phi^{* *}$ & & $\alpha^{*}$ & $\tau_{c}^{*}$ \\
\hline$\%)$ & $\left(\mathrm{J} / \mathrm{m}^{3}\right)$ & $(\mathrm{deg})$ & & $(\mathrm{s} / \mathrm{m})$ & $(\mathrm{Pa})$ \\
0 & 4.151 & 58.35 & & 0.2296 & 0.745 \\
0.2 & 4.463 & 59.74 & 0.0147 & 11.150 \\
0.4 & $4.754^{\mathrm{a}}$ & - & - & 25.891 \\
0.6 & 4.947 & 62.32 & & 0.0033 & 34.516 \\
1.2 & 6.097 & 64.64 & - & - \\
\hline
\end{tabular}

${ }^{\mathrm{a}}$ Values obtained from Eq. (38).

$$
\omega=\frac{6 \alpha^{*}}{G_{S} \rho_{w} V_{f}}\left\{\frac{q}{\pi D}\left[A^{*}\left(1-\frac{2}{3} \sin \phi^{\prime *} \tan \beta\right)\right]+\frac{G_{s} \rho_{w}}{12} V_{f}^{2}\right\}
$$

while neglecting the term $q \tau_{a} / 7 \pi^{2}[B+\pi(\beta \sin \beta)-x \pi \cos \beta]$ as a result of its insignificant numerical value. The efficiency factor for different flow velocities was calculated by substituting the parameters of treated and untreated soil given in Table 3. A normalized plot of the efficiency factor in terms of $A^{*}$ and $\tau_{c}^{*}$ is illustrated in Fig. 14 for both LS-treated and -untreated soil. A relationship for the efficiency factor was obtained from the best-fit line of Fig. 14 for LStreated and -untreated silty sand as 


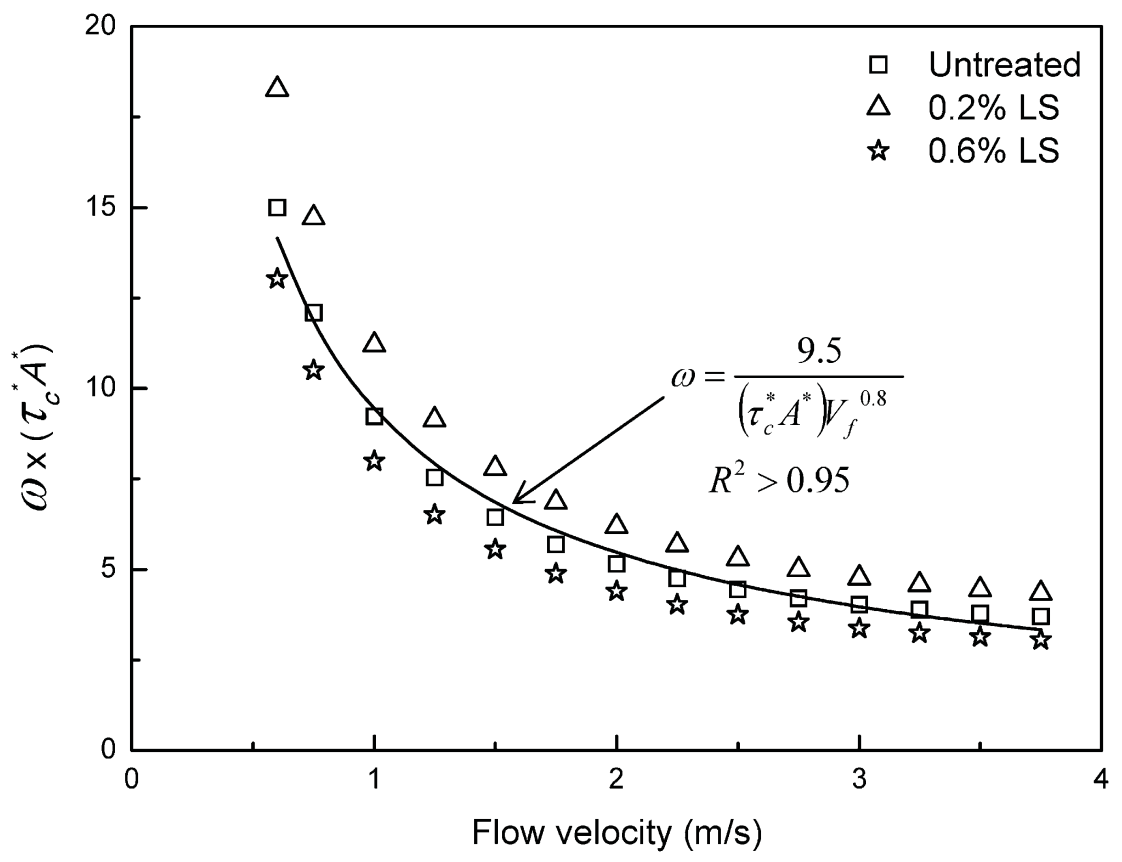

Fig. 14. Variation of efficiency factor normalized by $\tau_{c}^{*}$ and $A^{*}$ with the flow velocity

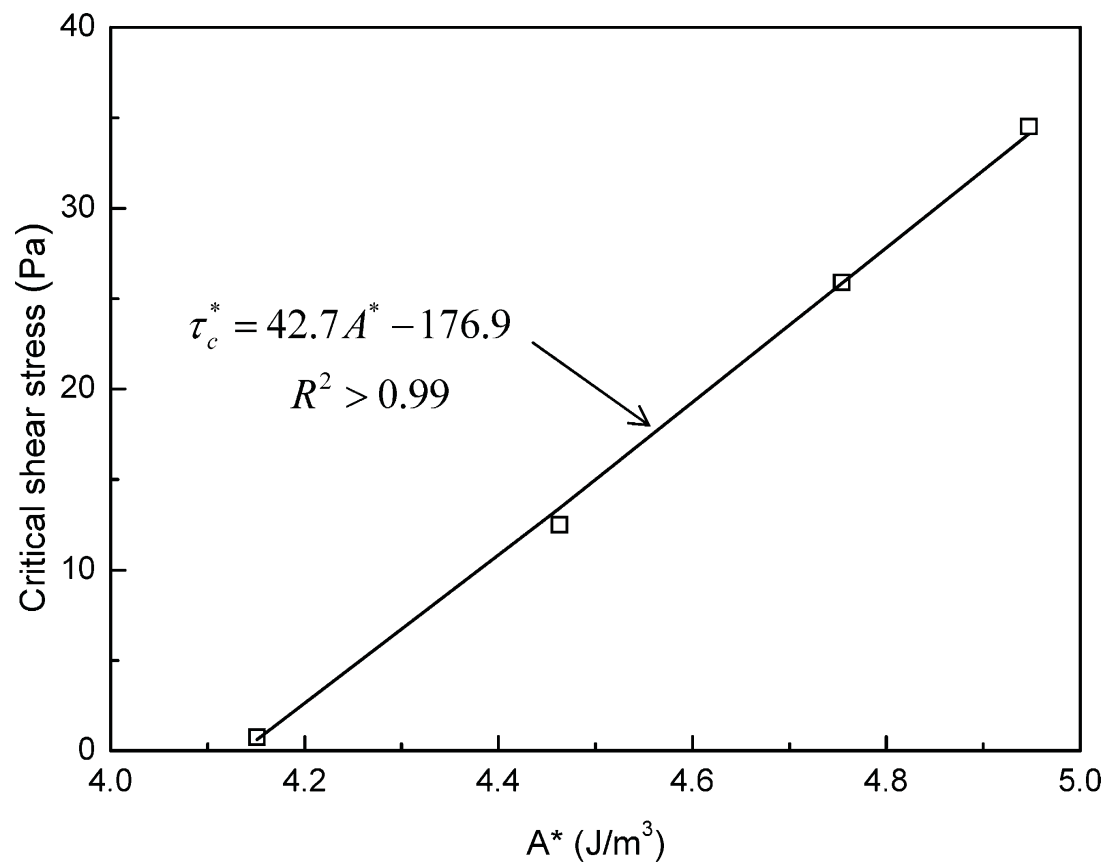

Fig. 15. Relationship of critical shear stress initiating erosion with the $A^{*}$ for silty sand treated with LS

$$
\omega=\frac{\lambda}{\left(\tau_{c}^{*} A^{*}\right) V_{f}^{(\eta)}}
$$

where $\lambda$ and $\eta=$ empirical constants with values of 9.5 and 0.8 , respectively.

Furthermore, from Fig. 15, a linear relationship was established for critical shear stress initiating erosion in terms of $A^{*}$

$$
\tau_{c}^{*}=b A^{*}-c
$$

where $b$ and $c=$ empirical constants with values of 42.7 and 177 , respectively.

To determine suitable values for $q$ and $\beta$, the packing arrangement of soil grains in compacted soil specimens should be identified. For this purpose, six possible systematic assemblages of spheres, as 
described by Gray (1968), were considered. Because the porosity of a compacted soil specimen should be smaller, only the particle arrangements that corresponded to low porosities were taken into account and shown in Fig. 16. The calculated values of $q$ and $\beta$ for the packing structures are also shown in Fig. 16. The specimens of silty sand used for both the direct-shear and erosion tests were prepared to achieve the same dry density (95\% MDD), whereas the porosity of those specimens was calculated to be $29 \%$. Therefore, the arrangement number 5 shown in Fig. 16 was identified as the closest possible packing structure for the specimens in this study.

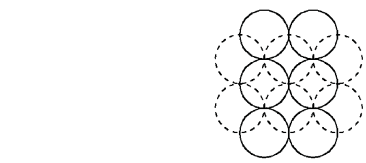

Packing number

Porosity (\%)

$q$

$\beta(\operatorname{deg})$
(3)

26.0

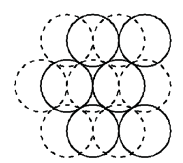

(5)

30.2

0.866

30

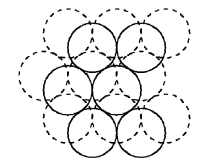

(6)

26.0

0.866

35.25
Fig. 16. Packing arrangements of spherical particles with lower porosities and their properties

Table 4. Independent Set of Data Used to Validate the Proposed Erosion Model

\begin{tabular}{lccccc}
\hline & \multicolumn{2}{c}{ Present study } & & \multicolumn{2}{c}{ Indraratna et al. (2008b) } \\
\cline { 2 - 3 } & $A^{*}$ & $\phi^{\prime *}$ & & $\alpha^{*}$ & $\tau_{c}^{*}$ \\
\hline$(\%)$ & $\left(\mathrm{J} / \mathrm{m}^{3}\right)$ & $(\mathrm{deg})$ & & $(\mathrm{s} / \mathrm{m})$ & $(\mathrm{Pa})$ \\
0.1 & $4.271^{\mathrm{a}}$ & $59.18^{\mathrm{b}}$ & & 0.0361 & 5.414 \\
0.4 & - & $60.75^{\mathrm{b}}$ & & 0.0064 & - \\
\hline
\end{tabular}

${ }^{\mathrm{a}}$ Values obtained from Eq. (38).

${ }^{\mathrm{b}}$ Values obtained from Eq. (37).
Consequently the values chose for $q$ and $\beta$ were 0.866 and $30^{\circ}$, respectively.

\section{Model Validation}

In addition to the relationships obtained for $\omega$ and $\tau_{c}^{*}$ as previously described, a relationship between $\phi^{\prime *}$ and percentage of LS (with $R^{2}>0.97$ ) was obtained from shear test results of untreated and 0.2 , 0.6 , and $1.2 \%$ LS-treated soil as

$$
\phi^{\prime *}=b_{1}(\mathrm{LS})+c_{1}
$$

where $b_{1}$ and $c_{1}=$ empirical constants with values of 5.23 and 58.66, respectively; and LS = amount of LS as a percentage of dry soil weight.

Another linear correlation between percentage of LS and $A^{*}$ was obtained through a best-fit line to the shear test results of untreated and $0.2,0.6$, and $1.2 \%$ LS-treated specimens (with $R^{2}>0.98$ ) as

$$
A^{*}=b_{2}(\mathrm{LS})+c_{2}
$$

where $b_{2}$ and $c_{2}=$ empirical constants with values of 1.61 and 4.112 , respectively.

Together with $q$ and $\beta$, these expressions explored for $\omega$ [Eq. (35)], $\tau_{c}^{*}$ [Eq. (36)], $\phi^{\prime *}$ [Eq. (37)], and $A^{*}$ [Eq. (38)] were substituted in Eq. (31) to predict the erosion rate of LS-treated $(0.1,0.2,0.4$, and $0.6 \% \mathrm{LS})$ and untreated silty sand. The independent set of data used to validate the proposed erosion model is shown in Table 4. The model predicted rates of erosion for untreated and treated silty sand were plotted against the applied hydraulic shear stress and compared with laboratory-observed erosion rates (Fig. 17); 0.1 and $0.4 \%$ LS-treated predictions were completely independent because these experimental results did not use parameter calculations (Table 4). Fig. 18 shows a comparison between the erosion parameters of untreated and treated soil obtained experimentally and predicted by the proposed model. It is evident from both Figs. 17 and 18 that the

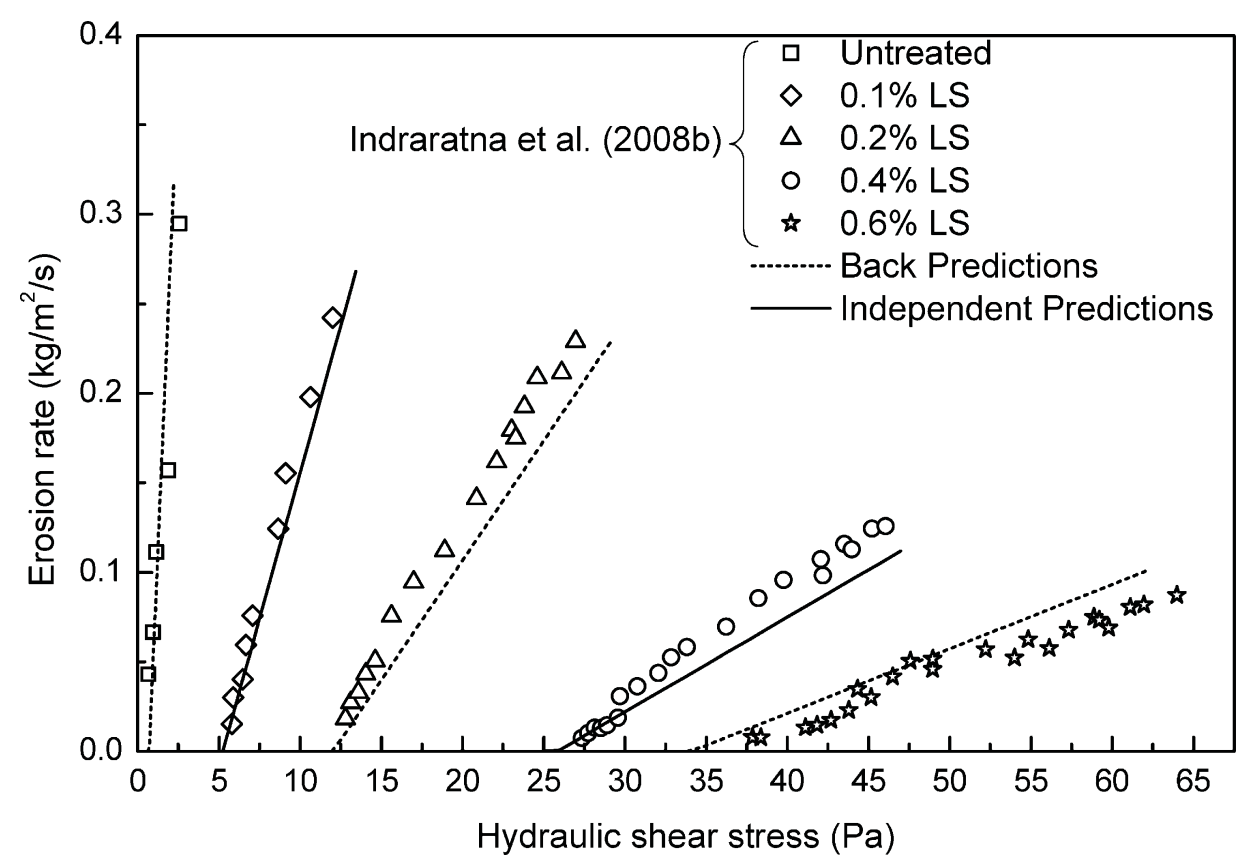

Fig. 17. Experimental and model predicted erosion rates with applied hydraulic shear stress for silty sand treated with LS 


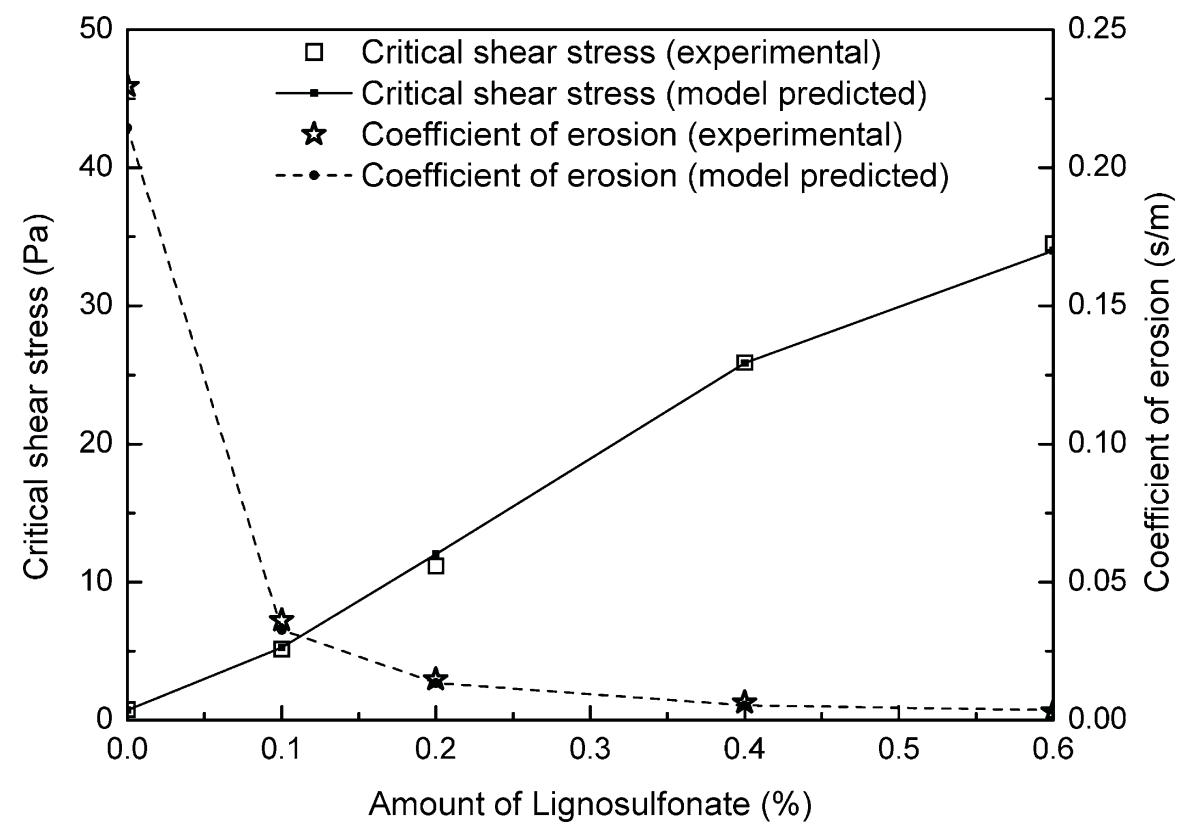

Fig. 18. Experimentally observed and model predicted erosion parameter with the dosage of LS

erosion model presented in this paper can capture the erosion of chemically stabilized soil.

\section{Conclusions}

This paper presents the development of a theoretical erosion model to predict the rate of erosion based on the principle of energy conservation. Using this proposed model, the rate of erosion can be determined if the packing arrangement of soil particles in compacted specimens, the shear characteristics, mean flow velocity, mean particle diameter, and specific gravity of the soil are known. In validating this erosion model, three possible packing arrangements of spherical particles corresponding to low porosities were considered to represent the compacted soils. From these structures, the one whose porosity was closest to that of the tested specimens was selected for both treated and untreated soils. LS was used to stabilize an erodible silty sand. Direct-shear experiments were conducted to obtain the stress-strain characteristics of treated and untreated (saturated) soil specimens. The experimental results showed that the peak shear strength and initial stiffness of the specimens were increased moderately because of treatment, and hence, the strain energy per unit volume up to peak was also increased. A linear relationship between the critical shear stress initiating erosion and strain energy per unit volume at zero effective normal stress was obtained from the experimental results. This expression was then used in the model to predict the rate of erosion of untreated and treated silty sand. It was found that the proposed erosion model could accurately represent the soil erosion of silty sand treated with LS.

This proposed erosion model can be used by practicing engineers to assess erosion-related problems. The surface and internal erosion of rail and/or road embankments, dam cores, and water channels are two of the foremost problems that must be considered when evaluating the safety of these earth structures. Using erodible and/ or dispersive soils in construction of earth structures is not appropriate, especially when they are in contact with water.
However, in some instances, this practice becomes inevitable, and therefore, the solution is to adopt suitable methodologies to reduce erosion. In this context, LS is proven to be an effective treatment. The proposed Eq. (31) can be used to obtain the relationship between erosion rates and applied hydraulic shear stress for silty sand treated with different amounts of LS. This helps practicing engineers to determine the amount of LS to be added to the material before compaction, to eliminate the possibility of erosion after construction. At this stage, engineers should have some idea of the possible maximum flow velocity or hydraulic gradient through cracks to calculate the possible maximum hydraulic shear stress through cracks.

\section{Acknowledgments}

The writers wish to express their gratitude to the Australian Research Council, Queensland Department of Transport and Main Roads (Brisbane) and to Robert Armstrong (Chemstab Consulting Pvt. Ltd., Wollongong) for providing financial support for this research. The assistance in laboratory experiments given by the technical staff at University of Wollongong is gratefully acknowledged.

\section{Notation}

The following symbols are used in this paper:

$A^{*}=$ area under the stress displacement curve of stabilized soil up to failure at zero effective normal stress;

$A_{e p}=$ effective area per particle on the shear surface;

$a_{r}=$ radial acceleration of the reference particle;

$B=$ area under the curve $f(\theta)$ from $\theta=0$ to $\theta=\pi$;

$b, c=$ empirical constants;

$b_{1}, c_{1}=$ empirical constants;

$b_{2}, c_{2}=$ empirical constants;

$D=$ mean particle diameter; 
$d_{s}=$ shear displacement;

$d_{s f}=$ shear displacement at failure;

$E_{b}=$ energy required per particle to break interparticle bonds;

$E_{b}^{*}=$ energy required per particle to break interparticle bonds after stabilization;

$E_{b i}=$ energy required to break the $i$ th interparticle bond;

$E_{d v}=$ energy required to erode a small $d v$ volume of soil;

$E_{T}=$ total energy required for erosion in $d t$ time;

$E_{\theta}^{*}=$ energy required to erode one stabilized soil particle at an angle $\theta$;

$F_{D}=$ drag force on a soil grain;

$F_{F}=$ friction force acting at the contact point;

$F_{i}=$ frictional resistance between the soil grains;

$F_{L}=$ lift force on a soil grain;

$F_{n i}=$ applied normal force on $i$ th contact;

$F_{s i}=$ applied shear force on $i$ th contact because of shearing;

$G_{s}=$ specific gravity of soil;

$g=$ gravitational acceleration;

$h_{0}=$ initial height of the specimen undergoing direct shear;

$I_{G}=$ moment of inertia of a soil grain about its center of gravity;

$k^{\prime}=$ average number of bonds per particle;

$l=$ length of the crack;

$m=$ mass of a soil particle;

$n=$ number of interparticle bonds in a unit surface area;

$N=$ number of particles in a unit volume;

$N_{F}=$ normal force on the reference particle at contact point;

$N_{i}=$ mobilized normal resistance at $i$ th contact;

$q=$ a constant depends on the packing arrangement of soil particles;

$r_{t}=$ radius of the crack at time $t$;

$S_{i}=$ mobilized shearing resistance at $i$ th contact along the failure surface;

$S_{n}=$ displacement of the particle normal to soil bed;

$S_{p}=$ displacement of the particle parallel to soil bed;

$V_{f}=$ mean flow velocity through crack;

$V_{n(0)}=$ velocity of the soil grain at bed level, normal to soil bed;

$V_{p(0)}=$ velocity of the soil grain at bed level, tangential to soil bed;

$V_{r}=$ radial velocity of the reference soil particle;

$V_{t}=$ tangential velocity of the reference soil particle;

$W D_{R}=$ work done in rolling the particle;

$W D_{S}=$ work done in suspension;

$W_{S}=$ submerged weight of a soil grain;

$x=$ ratio of lift force to drag force;

$\beta=$ angle of the reference particle to the vertical with respect to the contact particle;

$\gamma=$ shear strain;

$\gamma_{f}=$ shear strain at failure;

$\Delta E^{\prime}=$ energy dissipated by excess hydraulic shear stress in time $d t$;

$\delta d_{i}=$ displacement along the actual failure surface of $i$ th contact;

$\delta x_{i}=$ displacement of $i$ th contact along the average failure surface;

$\delta y_{i}=$ displacement of $i$ th contact normal to the average failure surface; $\dot{\varepsilon}=$ erosion rate;

$(\dot{\varepsilon})^{*}=$ erosion rate of stabilized soil;

$\theta=$ angle of the reference particle inside the crack with respect to the vertical plane through the axis of crack;

$\lambda, \eta=$ empirical constants;

$\mu_{i}=$ coefficient of friction between soil particles;

$\rho_{d}=$ dry density of soil specimen;

$\rho_{w}=$ density of water;

$\sigma_{n}^{\prime}=$ effective normal stress;

$\tau^{\prime}=$ effective shear resistance;

$\tau_{a}=$ applied hydraulic shear stress;

$\tau_{c}=$ critical shear stress initiating erosion;

$\tau_{c}^{*}=$ critical shear stress initiating erosion after stabilization;

$\phi^{\prime}=$ angle of internal friction of soil;

$\phi^{*}=$ angle of internal friction of stabilized soil;

$\psi=$ angle by which the reference particle rolled; and

$\psi_{\max }=$ angle by which the reference particle rolled when the contact is lost;

$\omega=$ efficiency factor; and

$\omega_{p}=$ angular velocity of the soil particle.

\section{References}

Arulanandan, K., Krone, R. B., and Loganathan, P. (1975). "Pore and eroding fluid influences on surface erosion of soil." J. Geotech. Engrg. Div., 101(1), 51-66.

Australian Standards. (1997). "Soil classification tests - dispersion - determination of pinhole dispersion classification of a soil." AS1289.3.8.3. Australian Standards, SAI Global Limited, Sydney, Australia.

Australian Standards. (2008). "Soil classification tests - dispersion determination of the percent dispersion of a soil." AS1289.3.8.2. Australian Standards, SAI Global Limited, Sydney, Australia.

Biggs, A. J. W., and Mahony, K. M. (2004). "Is soil science relevant to road infrastructure?" ISCO 2004 - 13th Int. Soil Conservation Organisation Conf., Conserving Soil and Water for Society: Sharing Solutions, Brisbane, Australia, Paper No. 410, 1-7.

Bishop, A. W. (1954). "Discussion: Shear characteristics of a saturated silt, measured in triaxial compression." Geotechnique, 4(1), 43-45.

Boardman, D. I., Glendinning, S., Rogers, C. D. F., and Holt, C. C. (2001). "In situ monitoring of lime-stabilized road subgrade." Geomaterials 2001: Soils, geology, and foundations, Transportation Research Board National Research Council, Washington DC, 3-13.

Briaud, J. L., Ting, F. C. K., Chen, H. C., Cao, Y., Han, S. W., and Kwak, K. W. (2001). "Erosion function apparatus for scour rate predictions." J. Geotech. Geoenviron. Eng., 127(2), 105-113.

Chen, R., Drnevich, V. P., and Daita, R. K. (2009). "Short-term electrical conductivity and strength development of lime kiln dust modified soils." J Geotech Geoenviron Eng., 135(4), 590-594.

Dunn, I. S. (1959). "Tractive resistance of cohesive channels." J. Soil Mech. Found. Div., 85(SM3), 1-24.

Gray, W. A. (1968). The packing of solid particles, Chapman and Hall Ltd, London.

Hjeldnes, E. I., and Lavinia, B. V. K. (1980). "Cracking, leakage and erosion of earth dam materials.” J. Geotech. Engrg. Div., 106(GT2), $117-135$.

Hubbe, M. A. (1985). "Detachment of colloidal hydrous oxide spheres from flat solids exposed to flow 2. Mechanism of release." Colloids Surf., 16(3-4), 249-270.

Indraratna, B. (1996). "Utilization of lime, slag and fly ash for improvement of a colluvial soil in New South Wales, Australia." Geotech. Geol. Eng., 14(3), 169-191.

Indraratna, B., Muttuvel, T., and Khabbaz, H. (2008a). "Investigating erosional behaviour of chemically stabilised erodible soils." Geocongress 
2008, Geo-Institute of ASCE, New Orleans, Geotechnical Special Publication, 178, 670-677.

Indraratna, B., Muttuvel, T., and Khabbaz, H. (2009). "Modelling the erosion rate of chemically stabilized soil incorporating tensile force deformation characteristics." Can. Geotech. J., 46(1), 57-68.

Indraratna, B., Muttuvel, T., Khabbaz, H., and Armstrong, R. (2008b) "Predicting the erosion rate of chemically treated soil using a process simulation apparatus for internal crack erosion." J. Geotech. Geoenviron. Eng., 134(6), 837-844.

Indraratna, B., Nutalaya, P., and Kugamenthira, N. (1991). "Stabilization of a dispersive soil by blending with fly ash." Quart. J. Eng. Geol. Hydrogeol, 24(3), 275-290.

James, G. (2010). Modern engineering mathematics, Pearson Education Limited, London.

Jaynes, D. B., Colvin, T. S., and Ambuel, J. (1995). "Yield mapping by electromagnetic induction." Proc., 2nd Int. Conf. on Site-Specific Management for Agricultural Systems, Madison, WI, 1, 386-394.

Kamphuis, J. W., and Hall, K. R. (1983). "Cohesive material erosion by unidirectional current.” J. Hydraul. Eng., 109(1), 49-61.

Karol, R. H. (2003). Chemical grouting and soil stabilization, 3rd Ed., Marcel Decker, Inc., New York.

Kitchen, N. R., Sudduth, K. A., and Drummond, S. T. (1996). "Mapping of sand deposition from 1993 midwest floods with electromagnetic induction measurements." J. Soil Water Conserv., 51(4), 336-340.

Lyle, W. M., and Smerdon, E. T. (1965). "Relation of compaction and other soil properties to erosion resistance of soils." Trans. ASAE, 8(3), 04190422.

Machan, G., Diamond, S., and Leo, E. (1977). "Laboratory study of the effectiveness of cement and lime stabilization for erosion control." Transportation Research Record, Transportation Research Board, Washington, DC, 641, 24-28.

Middleton, G. V., and Southard, J. B. (1978). Mechanics of sediment movement, Society of Economic Paleontologists and Mineralogists, New York.

Muttuvel, T. (2008). "Erosion rate of chemically stabilised soils incorporating tensile stress-deformation behaviour." Ph.D. thesis, School of Civil, Mining and Environmental Engineering, Univ. of Wollongong, Wollongong, Australia.

Nalbantoglu, Z., and Tuncer, E. R. (2001). "Compressibility and hydraulic conductivity of a chemically treated expansive clay." Can. Geotech. J., 38(1), 154-160.

Pengelly, A. D., Boehm, D. W., Rector, E., and Welsh, J. P. (1997). "Engineering experience with in-situ modification of collapsible and expansive soils." Unsaturated Soil Engineering Practice, ASCE Geotechnical Special Publication, ASCE, Reston, VA.Vol. 68, 277298.

Perry, J. P. (1977). "Lime treatment of dams constructed with dispersive clay soils." Trans. Am. Soc. Agricult. Eng., 20(6), 1093-1099.

Puppala, A. J., and Hanchanloet, S. (1999). "Evaluation of a new chemical (SA-44/LS-40) treatment method on strength and resilient properties of a cohesive soils." Proc., Transportation Research Board Annual Meeting, Transportation Research Board, Washington, DC.

Reddi, L., and Bonala, M. (1997). "Critical shear stress and its relationship with cohesion for sand-kaolinite mixtures." Can. Geotech. J., 34(1), 26-33.

Rollings, R. S., and Burkes, M. P. (1999). "Sulfate attack on cement stabilized sand." J. Geotech. Geoenviron. Eng., 125(5), 364-372.

Rosewel, C. J. (1977). "Identification of susceptible soils and control of tunnelling failure in small earth dams." Dispersive clays, related piping and erosion in geotechnical projects, ASTM STP 623. J. L. Sherard and R. S. Decker, eds. ASTM, West Conshohocken, PA, 362-369.

Ryker, N. L. (1977). "Encountering dispersive clays on soil conservation service projects in Oklahoma." Dispersive clays, related piping and erosion in geotechnical projects, ASTM STP 623. J. L. Sherard, and R. S. Decker, eds. ASTM, West Conshohocken, PA, 370-389.

Sargunan, A. (1976). "Influence of mineralogy, pore and eroding fluid composition on hydraulic erosion of cohesive soils." Indian Geotech. J., 6(3), 141-150.

Sariosseiri, F., and Muhunthan, B. (2009). "Effect of cement treatment on geotechnical properties of some Washington state soils." Eng. Geol., 104(1-2), 119-125.

Shaikh, A., Ruff, J. F., Charlie, W. A., and Abt, S. (1988). "Erosion rate of dispersive and nondispersive clays." J. Geotech. Engrg. Div., 114(5), 589-600.

Sharma, M. M., Chamoun, D. S. H. H., Sarma, S. R., and Robert, S. S. (1992). "Factors controlling the hydodynamic detachment of particles from surfaces.” J. Coll. Interface Sci., 149(1), 121-134.

Tingle, J. S., and Santoni, R. L. (2003). "Stabilization of clay soils with nontraditional additives." Transportation Research Record 1819 , Transportation Research Board, Washington, DC, 72-84.

Vinod, J. S., Indraratna, B., and Mahamud, M. A. A. (2010). "Stabilisation of an erodible soil using a chemical admixture." Proc., ICE - Ground Improv., 163(1), 43-51. 